\title{
Stereoselective Synthesis of Trisubstituted Alkenes via Intermolecular Olefin Metathesis
}

Metal-Catalyzed

Asymmetric

Synthesis and

Stereoselective

Reactions
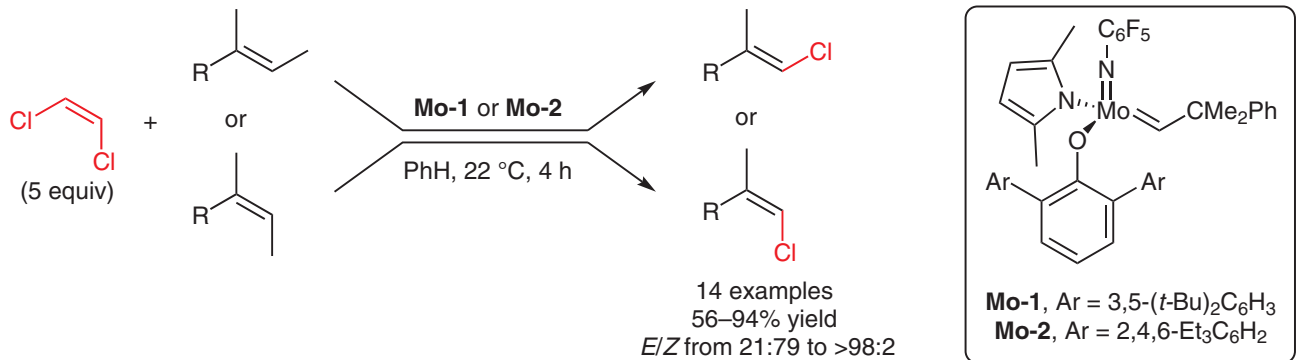

\section{Key words}

olefin metathesis

molybdenum

catalysis

alkenyl halides

14 examples

$56-94 \%$ yield

E/Z from $21: 79$ to $>98: 2$

Mo-2, $\mathrm{Ar}=2,4,6-\mathrm{Et}_{3} \mathrm{C}_{6} \mathrm{H}_{2}$

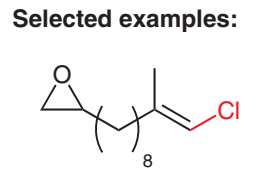

Mo-2 (5 mol\%) $56 \%$ yield, $E / Z=94: 6$<smiles>CC=CC=C(C)C=C[Pb]</smiles>

Mo-2 (10 mol\%) $86 \%$ yield, $E / Z=95: 5$<smiles>COc1cccc(/C(C)=C/Cl)c1</smiles>

Mo-1 (5 mol\%) $87 \%$ yield, $E / Z>98: 2$<smiles>COc1cccc(/C(C)=C\Cl)c1</smiles>

Mo-1 (5 mol\%) $65 \%$ yield, $E / Z=21: 79$

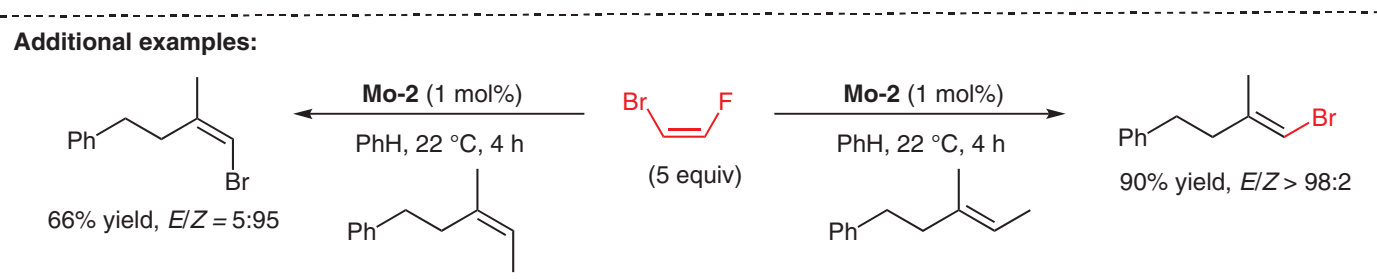

Stereochemical model:

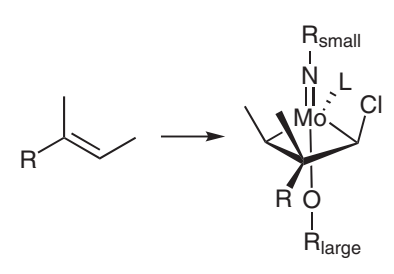

favored

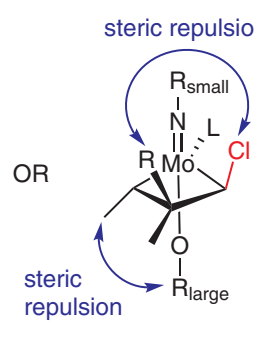

teric repulsion

repulsior

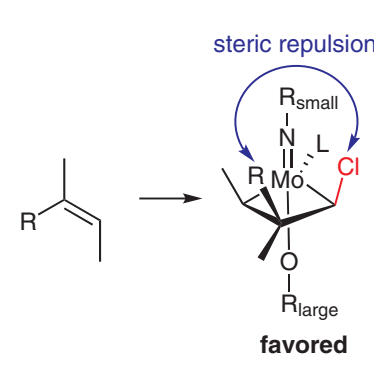

$\mathrm{L}=2,5$-dimethylpyrrole

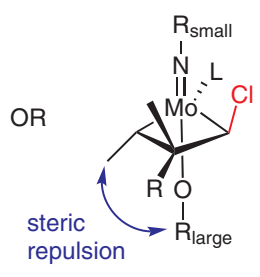

Significance: Crossed olefin metathesis is a challenge in organic chemistry because of the prevalence of side reactions from homo-metathesis. Hoveyda and co-workers report a crossed metathesis with high $E / Z$-selectivity generating trisubstituted haloalkenes. The reaction shows good to excellent $E / Z$-selectivity and can generate either the $E$ or $Z$ product depending on the stereochemistry of the starting olefin.

SYNFACTS Contributors: Mark Lautens, Andrew Whyte Synfacts 2018, 14(03), 0261 Published online: 15.02.2018 Dol: 10.1055/s-0037-1609296; Reg-No.: L01118SF
Comment: Alkenyl chloride products could be generated in good to excellent yields wherein the trans product was formed with higher $E / Z$ ratios. Additionally, the alkenyl bromide products could be generated. The improved selectivity for the trans-olefin starting material was explained with the stereochemical model. In the case of the $Z$ olefin, the energy gap between the two potential pathways is less because steric repulsion is significant in both pathways, leading to lower E/Z ratios. 